\title{
Assessment of Healthful Lifestyle Behaviors between Graduate Programs
}

Erik Vincek,' Dana Angelo White,' Richard Feinn.'

\begin{abstract}
Background: Heart disease is a condition with many etiologies, some of which include genetics, obesity, exercise, diet, smoking, and alcohol use. Studies show that increased years of education lead to better health outcomes, specifically lower rates of heart disease and obesity. Despite their high level of education, physicians have been shown to have a disproportionally higher rate of heart disease. Our objective was to determine whether there are particular lifestyle habits present among medical students that may lead to increased risk of heart disease as their academic and clinical futures progress. Methods: 201 Quinnipiac University medical, law, and education graduate students were recruited to this survey study. Descriptive statistics were used to present the data. Chi-squared test and Kruskal-Wallis tests were used to test the significance and a p-value 0.05 was considered significant. Results: Medical students were able to answer health-related questions correctly more than their law and education student counterparts ( $p$-value $<.001)$, felt able to explain the terms saturated fat ( $p$-value <.001) and trans-fat ( $p$-value <.001) and give an accurate estimate of personal BMI status better than their counterparts in the law and education programs, but did not significantly differ in meeting Dietary Approaches to Stop Hypertension (DASH) diet recommendations or American Heart Association (AHA) recommendations for physical activity. Conclusion: Increased health-related knowledge has little bearing on individual dietary and physical activity habits of graduate students. We found no evidence to show that increased medical knowledge leads individuals to pursue lifestyle habits that lower the risk of heart disease.
\end{abstract}

Key Words: Medical Students; Cardiovascular Diseases; Heart Diseases; Health Behaviors; DASH Diet (Source: MeSH-NLM).

\section{Introduction}

In the United States, heart disease is the number one cause of death. ${ }^{1}$ obesity, history of smoking, lack of exercise, and poor diet are just a few of the factors that contribute to heart disease in the United States. According to a Health United States Report 2016 estimate, $70.7 \%$ of Americans aged 20 and over are overweight or obese, and in 2014 only half of American adults met the American Heart Association requirements for aerobic physical activity, based on self-report. ${ }^{2-3}$. Additionally, about one third of coronary heart disease deaths are attributable to smoking or exposure to second-hand smoke. ${ }^{3}$

Various diets are known to be better for long-term heart health. It has been shown that diets using non-hydrogenated unsaturated fats instead of saturated fats, whole grains as the predominant source of carbohydrates, and inclusion of adequate fruits and vegetables can lower the risk of cardiovascular disease (CVD).4-6 The Dietary Approaches to Stop Hypertension diet includes the incorporation of fatfree and low-fat dairy products, poultry and fish, beans, nuts, fruits and vegetables, and vegetable oils into the diet, while limiting the intake of sugar-sweetened products and sodium. The DASH diet has been shown to lower blood pressure and LDL cholesterol, and is endorsed by the AHA and National Heart, Lung, and Blood Institute. There is strong evidence that hypertension is a predominant contributor to CVD, thus population adherence to DASH diet recommendations is important to investigate..$^{7-8}$

Studies have shown that increased socioeconomic status and years of education lead to better health outcomes, specifically lower rates of chronic heart disease, obesity rates, and smoking.9-11. Some of this variation may be due to differences in diet and levels of physical activity. Physical activity is positively correlated with vascular health and reduces the lifetime risk of developing CVD. ${ }^{12}$ Adopting a regular exercise routine can have immediate benefits, including weight loss, fat loss, increased cardio-respiratory fitness, and longevity. ${ }^{13}$

Despite the correlation between higher levels of education and greater long-term health, several studies have shown that physicians have a particularly increased risk for cardiovascular disease and are at greater risk for CVD than nurses working in the same healthcare setting. ${ }^{14-16}$ Additionally, studies have shown higher rates of depression and suicidal ideation among physicians compared to the general population ${ }^{17-19}$. These findings are paradoxical to those that suggest that a greater level of education leads to greater health outcomes. To determine when and how these increased risks develop, it may prove important to investigate whether there are already changes in lifestyle behaviors during medical school which might facilitate unexpectedly higher risks of CVD later in physicians' careers.

Controlling for years of education, we sought to compare medical students to counterparts who were at an identical graduate level of education. First and second year Quinnipiac University law and education graduate students were compared to first and second year Quinnipiac University medical students to determine whether the three graduate programs showed similar trends in heart-healthful lifestyle behaviors. We assessed heart-healthful lifestyle choices via adherence to recommendations from the American Heart Association and the DASH diet.

\section{Methods}

A cross-sectional study was conducted during the 2017-2018 academic school year on Quinnipiac University medical students, law students, and School of Education graduate students using a self-administered questionnaire.

${ }^{1}$ Frank H. Netter M.D. School of Medicine, Quinnipiac University, North Haven, USA.

About the Author: Erik Vincek is a $2^{\text {nd }}$ year medical student at Frank H. Netter M.D. School of Medicine, Quinnipiac University, USA.

Correspondence:

Erik Vincek

Address: Frank H. Netter M.D. School of Medicine, Quinnipiac University, North Haven, USA.

Email: evincek24@gmail.com
Editor: Mihnea-Alexandru Găman Submission: Aug 9, 2018 Acceptance: Dec 23, 2018 Publication: Dec 24, 2018 Process: Peer-reviewed 
A paper questionnaire was designed by the authors, which included 29 questions, the content of which included questions regarding dieting habits, exercise levels, and general health knowledge (see Appendix). Four questions were considered general health questions, fifteen questions assessed dietary habits, three questions assessed physical activity levels, three questions assessed individuals' perceived knowledge, and four questions were used to establish a profile of the students that included age, height, weight, gender, and perceived BMI. The students were assured that survey responses would remain anonymous. A complete written informed consent form was received from each participant in the study upon acknowledgement that the survey responses would be used for research purposes only. No names were collected in this study. Each questionnaire was distributed in person to the subjects on the campus of Quinnipiac University. This study was approved by the Quinnipiac University IRB (approval no. 04418).

Collected data was tested using the program IBM SPSS Statistics 25 . The students were placed into groups based on their graduate area of study (education, law, medicine). To compare significance among student groups, a Chi-squared test was used for nominal variables, KruskalWallis tests were used for ordinal variables, and a one-way ANOVA for continuous variables. Continuous variables were checked for normality. A p-value of $<0.05$ was considered statistically significant.

\section{Results}

The participants in this study included 201 graduate students affiliated with Quinnipiac University. $50(24.8 \%)$ were education students, 53 $(26.4 \%)$ were law students, and $98(48.76 \%)$ were medical students. The mean age of students in this study was 25.0 years. Mean ages and BMI of students in each program are shown in Table 1. There was a significant difference in mean BMI between programs ( $p$-value 0.008), of which medical students had the lowest score. Using a post-hoc Bonferroni comparison, the mean BMI between the law program and medical program was significantly different ( $p$-value 0.006 ), but there was not a significant difference between the mean BMI of the education program and law program, or between the education program and medical program. No significant difference was found in smoking and alcoholic drinking habits between programs.

Table 1. Mean Age and BMI of Students in Each Program ( $\mathrm{N}=201)$.

\begin{tabular}{lllll}
\hline & Education & Law & Medicine & P-value \\
\hline $\begin{array}{l}\text { Mean } \\
\text { Age }\end{array}$ & $23.46 \pm 2.12^{\mathrm{a}}$ & $24.57 \pm 3.38$ & $26.03 \pm 2.78$ & $<0.001$ \\
$\begin{array}{l}\text { Mean } \\
\text { BMI }\end{array}$ & $24.36 \pm 3.77$ & $26.09 \pm 5.96$ & $23.72 \pm 3.80$ & 0.008 \\
\hline
\end{tabular}

Legend: a Numbers in parenthesis specify standard deviation.

Three questions assessed students' perception of their own knowledge. A significant difference was found between programs in two of three of these questions. A significant difference existed in the proportion of students that felt they could explain the definition of a saturated fat ( $p$-value $<0.001$ ) and a trans-fat ( $p$-value $<0.001$ ). No significant difference existed in the proportion of students that felt they could explain the difference between natural and added sugar ( $P$-value 0.132). These results are represented in Table 2.

Four questions in the survey asked how often students think about limiting sugar intake, saturated fat, trans fat, and sodium intake. There was only a significant difference between programs in responses to "When making food choices, how often do you think about limiting your intake of trans fat?" (p-value $<0.001$ ). Results from this question
Table 2. Percentage of Students in Each Program Who Answered "Yes" to Each Perceived Knowledge Question.

\begin{tabular}{lllll}
\hline Question & Education & Law & Medicine & P-value \\
\hline Do you feel that you & $28.0 \%$ & $24.5 \%$ & $93.9 \%$ & $<0.001$ \\
could accurately explain & & & & \\
to a friend or colleague & & & \\
the definition of a & & & \\
saturated fat? & & & & \\
Do you feel that you & $22.0 \%$ & $26.4 \%$ & $92.9 \%$ & \\
could accurately explain & & & & \\
to a friend or colleague & & & \\
the definition of a trans- & & & \\
fat? & & & \\
Do you feel that you & $72.0 \%$ & & \\
could accurately explain & & & \\
to a friend or colleague & & & \\
the difference between \\
the terms "natural \\
sugar" and "added \\
sugar"?
\end{tabular}

are shown in Table 3. Of the questions related to dietary habits, only "On average, how many servings of nuts, seeds, or dry beans do you consume weekly?" yielded a significant difference between groups ( $p$ value 0.002 ).

Table 3. Responses to "When Making Food Choices, How Often Do You Think about Limiting Your Intake of Trans Fat?"

\begin{tabular}{llllll}
\hline Program & Never & Rarely & Sometimes & $\begin{array}{l}\text { Most of the } \\
\text { time }\end{array}$ & Always \\
\hline Education & $20.0 \%$ & $30.0 \%$ & $16.0 \%$ & $28.0 \%$ & $6.0 \%$ \\
Law & $15.1 \%$ & $13.2 \%$ & $39.6 \%$ & $20.8 \%$ & $11.3 \%$ \\
Medicine & $8.2 \%$ & $14.3 \%$ & $16.3 \%$ & $36.7 \%$ & $24.5 \%$ \\
\hline
\end{tabular}

There was no significant difference between groups meeting the overall AHA recommendation for physical activity. There was also no significant difference between the study groups meeting individual components of the AHA physical activity recommendation. Table 4 shows the percentage of students in each group that met the AHA recommendation and percentage that met each component of the AHA recommendation.

Table 4. Percentage of Students in Each Program Who Met Individual Components and Overall AHA Recommendations for Physical Activity.

\begin{tabular}{lllll}
\hline Program & $\begin{array}{l}\text { Meet } \\
\text { vigorous } \\
\text { aerobics } \\
\text { component }\end{array}$ & $\begin{array}{l}\text { Meet } \\
\text { moderate } \\
\text { aerobics } \\
\text { component }\end{array}$ & $\begin{array}{l}\text { Meet muscle- } \\
\text { strengthening } \\
\text { component }\end{array}$ & $\begin{array}{l}\text { Meets } \\
\text { overall AHA } \\
\text { requirement }\end{array}$ \\
\hline Education & $54.0 \%$ & $12.0 \%$ & $76.0 \%$ & $64.0 \%$ \\
Law & $52.8 \%$ & $9.4 \%$ & $79.3 \%$ & $66.0 \%$ \\
Medicine & $33.6 \%$ & $17.4 \%$ & $61.2 \%$ & $52.0 \%$ \\
\hline
\end{tabular}

Four questions assessed general health knowledge of the participants. Each one of these questions was answered correctly by medical students significantly more than by students in the other groups. Medical students also answered a significantly higher total number of health-related questions correctly compared to the other two groups ( $p$-value $<0.001)$. Table 5 show results from these questions. 
Table 5. Percentage of Students Who Responded to Each Health-Related Question Correctly and Mean Number of Health-Related Questions Answered Correctly.

\begin{tabular}{|c|c|c|c|c|}
\hline Question & Education & Law & Medicine & P-Value \\
\hline $\begin{array}{l}\text { "What is the number } \\
\text { one killer of } \\
\text { Americans?" }\end{array}$ & $68.0 \%$ & $88.7 \%$ & $94.9 \%$ & $<0.001$ \\
\hline $\begin{array}{l}\text { "What is the effect } \\
\text { of increased sodium } \\
\text { intake on blood } \\
\text { pressure?" }\end{array}$ & $98.0 \%$ & $88.7 \%$ & $100.0 \%$ & 0.001 \\
\hline $\begin{array}{l}\text { "How many } \\
\text { milligrams of } \\
\text { sodium are in one } \\
\text { teaspoon of salt?" }\end{array}$ & $40.0 \%$ & $28.3 \%$ & $49.0 \%$ & 0.047 \\
\hline $\begin{array}{l}\text { "A healthy daily } \\
\text { intake of sodium (in } \\
\text { milligrams) falls into } \\
\text { which range?" }\end{array}$ & $34.0 \%$ & $39.6 \%$ & $57.1 \%$ & 0.014 \\
\hline $\begin{array}{l}\text { Mean \# of health- } \\
\text { related questions } \\
\text { answered correctly }\end{array}$ & $\begin{array}{l}2.40 \\
( \pm 0.904)\end{array}$ & $\begin{array}{l}2.45 \\
( \pm 0.774)\end{array}$ & $\begin{array}{l}3.01 \\
( \pm 0.780)\end{array}$ & $<0.001$ \\
\hline
\end{tabular}

\section{Discussion}

With heart disease's global impact on patients and health-care systems, it is well worth investigating the trends that may lead certain populations to have less risk for cardiovascular disease. Studies have shown that a higher level of education leads to greater health outcomes, including lower rates of heart disease.9-11 The authors believed that an important reason for this trend was greater access and adherence to healthy diets and fitness regimens as well as increased knowledge of healthy lifestyle habits. This study revealed several characteristics of the physical activity level, dietary habits, and general health-knowledge between Quinnipiac University graduate students.

Despite a curriculum that strongly emphasizes the importance of healthy eating and exercise in terms of heart and overall health, Quinnipiac University medical students failed to surpass their peers in either category. Medical students answered significantly more healthrelated questions correctly, yet it seemed to have little bearing on their dietary habits. There was no significant difference in any of the dietary habits between the programs, except for the number of servings of nuts, seeds, and dry beans consumed weekly. This is one of several findings that may seem hypocritical of medical students and is a recurring theme of this study: medical students that are expected to become the primary source of health management for countless of patients fail to incorporate into their own lives what they are taught in medical school. If medical students and physicians are unable to follow their own advice, it seems unfair that we should expect patients to follow such advice. It might not be a stretch to suggest that improving medical student and physician adherence to healthy lifestyle behaviors may increase their patients' likelihood to do so as well.

Despite the findings regarding dietary habits, medical students had a lower BMI than both other groups. Although studies have shown that lower BMI is correlated with lower rates of coronary heart disease, high variability in body structure and composition among individuals continues to make BMI an uncertain predictor of heart health, and thus this finding was not used as a primary indicator of heart health in this study. ${ }^{20}$

Medical students were more likely to feel they could explain the definition of a saturated fat and trans-fat, but were similar in thinking about limiting saturated fat intake. Medical students were also able to answer correctly the range of the healthy amount of daily sodium intake and the range of the amount of sodium in one teaspoon of salt more than individuals from the other programs, but there was no difference in thinking about limiting sodium intake, despite the wellknown negative consequences of a high sodium diet on heart health of which is heavily reinforced in the medical school curriculum. Knowing about daily sodium intake recommendations has been shown to increase the likelihood of individuals using nutrition labels to make healthier food choices ${ }^{21}$. The authors' reasoning for this finding is that even with more health knowledge, medical students may not have sufficient time or money to cook healthy meals during a demanding curriculum and constricted budget. High stress levels, common in medical students, have been shown to be associated with unhealthy eating and obesity and may be impacting their dietary choices negatively. 22-24. These results suggest that education itself is not the sole factor facilitating healthy dietary and physical activity habits.

There was no significant difference in meeting the AHA recommendations for physical activity. Worth mentioning however is that the proportion of medical students who met the AHA recommendation for vigorous aerobics and that for muscle strengthening activity, as well as the overall AHA requirement for physical activity, was lower in medical students than in both other groups. A potential reason for this finding could be a difference between the medical student and law or education student schedule; however, individual schedules outside of required curriculum are variable and cannot be assumed.

Although it would be expected that medical students would practice healthier lifestyle habits due to their greater health knowledge, our results suggest otherwise and point to the previous research that shows that physicians are not healthier than the general public. We would expect that medical students and physicians who devote thei careers to improving the health of others would have the willingness and ability to improve their own health, but for undetermined reasons they fail to do so. To help up-and-coming physicians improve their own health, research is required to determine why physicians in particular are experiencing increased CVD risk and if it may be due to habits that are already present in the cradle of their medical careers.

The primary limitation of this study was that the findings were based on an anonymous survey and thus self-report bias may have existed. ${ }^{25}$ This study was a representation of the students at a single point in time and only included students from one university. Future studies with more students and that involve more universities could provide more information on the dietary and physical exercise habits of graduate students.

Even though there was potential for self-report bias, the anonymity provided by the survey may have allowed the students to give more accurate responses about personal information such as their lifestyle habits. Future studies may also benefit from including survey questions regarding stress levels, number of hours spent in mandatory classroom events, and number of hours spent studying outside of mandatory classroom events. 


\section{References}

1. Co AS, Mozaffarian D, Roger VL, Benjamin EJ, Berry JD, Blaha MJ, et al. Executive summary: heart disease and stroke statistics--2014 update: a report from the American Heart Association. Circulation. 2014 Jan 21;129(3):399-410.

2. National Center for Health Statistics (US). Health, United States, 2016: With Chartbook on Long-term Trends in Health. Hyattsville (MD): National Center for Health Statistics (US); 2017 May.

3. Writing Group Members, Mozaffarian D, Benjamin EJ, Co AS, Arnett DK, Blaha MJ, et al. Executive Summary: Heart Disease and Stroke Statistics--2016 Update: A Report From the American Heart Association. Circulation. 2016 Jan 26;133(4):447-454.

4. Cuasch-Ferre M, Babio N, Martinez-Conzalez MA, Corella D, Ros E, Martin-Pelaez S, et al. Dietary fat intake and risk of cardiovascular disease and all-cause mortality in a population at high risk of cardiovascular disease. Am J Clin Nutr. 2015 Dec;102(6):15631573.

5. Li B, Zhang G, Tan M, Zhao L, Jin L, Tang X, et al. Consumption of whole grains in relation to mortality from all causes, cardiovascular disease, and diabetes: Doseresponse meta-analysis of prospective cohort studies. Medicine (Baltimore). 2016 Aug;95(33):e4229.

6. Hartley L, Igbinedion E, Holmes J, Flowers N, Thorogood M, Clarke A, et al. Increased consumption of fruit and vegetables for the primary prevention of cardiovascular diseases. Cochrane Database Syst Rev. 2013 Jun 4;(6):CDo09874.

7. Siervo M, Lara J, Chowdhury S, Ashor A, Oggioni C, Mathers JC. Effects of the Dietary Approach to Stop Hypertension (DASH) diet on cardiovascular risk factors: a systematic review and meta-analysis. $\mathrm{Br}$ J Nutr. 2015 Jan 14;113(1):1-15.

8. Lewington S, Lacey $B$, Clarke R, Guo Y, Kong XL, Yang L, et al. The Burden of Hypertension and Associated Risk for Cardiovascular Mortality in China. JAMA Intern Med. 2016 Apr;176(4):524-532.

9. Hahn RA, Truman BI. Education Improves Public Health and Promotes Health Equity. Int J Health Serv. 2015;45(4):657-678.

10. Loucks EB, Gilman SE, Howe C], Kawachi I, Kubzansky LD, Rudd RE, et al. Education and coronary heart disease risk: potential mechanisms such as literacy, perceived constraints, and depressive symptoms. Health Educ Behav. 2015 Jun;42(3):370-379.

11. Boing AF, Subramanian SV. The influence of area-level education on body mass index, waist circumference and obesity according to gender. Int J Public Health. 2015 $\operatorname{Sep} ; 60(6): 727-736$.
12. antos-Parker JR, LaRocca TJ, Seals DR. Aerobic exercise and other healthy lifestyle factors that influence vascular aging. Adv Physiol Educ. 2014 Dec;38(4):296-307.

13. Ho SS, Dhaliwal SS, Hills AP, Pal S. The effect of 12 weeks of aerobic, resistance or combination exercise training on cardiovascular risk factors in the overweight and obese in a randomized trial. BMC Public Health. 2012 Aug 28;12:704-2458-12-704.

14. Hegde SB, Vijayakrishnan C, Sasankh AK, Venkateswaran S, Parasuraman C. Lifestyle-associated risk for cardiovascular diseases among doctors and nurses working in a medical college hospital in Tamil Nadu, India. J Family Med Prim Care 2016;5:281. 5

15. Jardim, Thiago Veiga et al. "Comparison of Cardiovascular Risk Factors in Different Areas of Health Care Over a 20-Year Period." Arquivos Brasileiros de Cardiologia 103.6 (2014): 493-501. PMC. Web. 13 Oct. 2018

16. Nobahar, Monir \& Reza Razavi, Mohammad. (2015). Lifestyle and the Most Important Risk Factors of Cardiovascular Disease in Physicians, Nurses, and Faculty Members. Middle East J Rehabil Health. 2015 Apr; 1-9.

17. Steven Stack (2004) Suicide Risk Among Physicians: A Multivariate Analysis, Archives of Suicide Research, 8:3, 287-292.

18. Zoccolillo, Mark et al. Depression among medical students. Journal of Affective Disorders, Volume 11, Issue 1. 1986 Jul-Aug; 91 - 96.

19. Kamski, L., Frank, E. at Wenzel, V. Anesthesiologist (2012) 61: 984.

20. Mongraw-Chaffin ML, Peters SAE, Huxley RR, Woodward M. The sex-specific association between BMI and coronary heart disease: a systematic review and metaanalysis of 95 cohorts with 1.2 million participants. The Lancet Diabetics it Endocrinology. 2015;3(6):437-49.

21. Dewey G, Wickramasekaran RN, Kuo T, Robles B. Does Sodium Knowledge Affect Dietary Choices and Health Behaviors? Results From a Survey of Los Angeles County Residents. Prev Chronic Dis 2017;14:170117.

22. Dahlin M, Joneborg N, Runeson B. Stress and depression among medical students: a cross-sectional study. Med Educ. 2005 Jun;39(6):594-604.

23. Supe AN. A study of stress in medical students at Seth G.S. Medical College. Postgrad Med. 1998 Jan-Mar;44(1):1-6.

24. Torres SJ, Nowson CA. Relationship between stress, eating behavior, and obesity Nutrition. 2007 Nov-Dec;23(11-12):887-894.

25. Althubaiti A. Information bias in health research: definition, pitfalls, and adjustment methods. J Multidiscip Healthc. 2016 May 4;9:211-217.

\section{Acknowledgments}

None.

Conflict of Interest Statement a Funding

The Authors have no funding, financial relationships or conflicts of interest to disclose.

Author Contributions

Conception and design the work/idea: EV. Collect data/obtaining results: EV. Analysis and interpretation of data: EV, RF. Write the manuscript: EV. Critical revision of the manuscript: EV, RF, DW. Approval of the final version: EV, RF, DW. Statistical advice: RF.

Cite as:

Vincek E, White D, Feinn R. Assessment of Healthful Lifestyle Behaviors between Graduate Programs. Int J Med Students. 2018;6(3):98-101. This work is licensed under a Creative Commons Attribution 4.0 International License 